DOI 10.20396/temáticas.v27i53.11607

\title{
A AÇÃO SINDICAL PETROLEIRA NOS GOVERNOS DO PARTIDO DOS TRABALHADORES (2003-2016)
}

RESUMO: O presente artigo oferece uma visada sobre a ação da Federação Única dos Petroleiros (FUP) durante os governos do Partido dos Trabalhadores (PT). Com base no recente debate sobre o comportamento do sindicalismo ao longo desses anos, e a observação do posicionamento político dos petroleiros na política de desenvolvimento econômico-social dos governos dos dois presidentes do PT, pretendemos ampliar a compreensão acerca do elo entre os governos petistas e trabalhadores nos anos 2000.

PALAVRAS-CHAVE: Sindicalismo; Petroleiros; Partido dos Trabalhadores.

\section{THE OIL WORKERS' TRADE UNION ACTION DURING THE PRESIDENTIAL MANDATES OF WORKERS' PARTY (2003-2016)}

\begin{abstract}
This essay offers a panorama about the action of the Unique Federation of Oil Workers (Federação Única dos Petroleiros, FUP) during the Workers' Party (Partido dos Trabalhadores, PT) presidential mandates. By focusing on the recent debate about the trade unionism and on the political position of oil workers regarding social-economic development during PT government, this essay aims at expanding the comprehension about the bonds between that party and the oil workers in 2000 first decade.

KEYWORDS: Trade Unionism; Oil Workers; Workers’ Party.

\footnotetext{
${ }^{1}$ Doutorando associado ao Laboratório de Estudos sobre Trabalho, Profissões e Mobilidade (LEST-M) do Programa de Pós-Graduação em Sociologia da Universidade Federal de São Carlos (PPGS-UFSCar). Contato: danilolcnmnds@gmail.com
} 


\section{INTRODUÇÃO}

A FUP foi criada em 1994 para assumir a representação, em nível nacional, dos sindicatos dos trabalhadores da indústria de petróleo. Contudo, os esforços para promover a organização dos interesses da categoria petroleira nacionalmente, rompendo com a descentralização das negociações imposta pela estrutura sindical corporativa, foram antecedidos pelo Comando Nacional dos Petroleiros (1986) e pela Federação Única Cutista Petroleira (1993).

No ano de 1995, a FUP articulou a maior greve da história da categoria petroleira, a mais longa do setor de petróleo e gás no mundo. Foram 31 dias consecutivos, de dois de maio até três de junho. O motivo dominante era barrar a quebra do monopólio da Petrobras. A greve foi encerrada com a ocupação das refinarias pelas forças armadas. Foram demitidos 95 petroleiros e o sindicato foi judicialmente emparedado: contas bloqueadas e bens penhorados (ROMÃO, 2006).

Nos anos 2000, a relação histórica dos petroleiros com o Partido dos Trabalhadores (PT) foi reforçada quando, na composição do primeiro governo do presidente Lula, o ex-petroleiro José Eduardo Dutra assumiu a presidência da Petrobras.

No ano de 2003, em seu $9^{\circ}$ Congresso Nacional (CONFUP) os petroleiros exortaram o novo governo a tomar as medidas necessárias para a realização do seu projeto que, no limite, implicaria na volta da estatal para o controle absoluto do Estado. De modo intermediário, a mensagem consistia na defesa de que a Petrobras assumisse um papel estratégico no desenvolvimento econômico da nação.

De fato, segundo Fiori (2019), entre 2003 e 2015,

a Petrobras se transformou numa peça-chave do desenvolvimento econômico do país, chegando a ser responsável por cerca de $13 \%$ do Produto Interno Bruto (PIB) brasileiro e $8,4 \%$ da formação bruta do seu capital fixo, com um investimento (...) de 1,6\% do PIB brasileiro (FIORI, 2019, p. 31). 
Contudo, na ocasião da regulamentação do setor de petróleo, em 2010, os petroleiros não tiveram êxito na tentativa de emplacar um marco regulatório que restituísse a Petrobras como uma empresa totalmente estatal.

Essa contradição enseja questionar a ação sindical petroleira. Os petroleiros não conseguiram atingir plenamente os seus objetivos, mas não abandonaram o governo, tampouco deixaram de defender o seu projeto. Nesse sentido, qual o significado da ação dos petroleiros nos governos do Partido dos Trabalhadores?

Antes de esboçar uma resposta para essa questão, faremos uma incursão pelo debate acerca das relações do sindicalismo com os governos do PT; em seguida, retomaremos a relação dos petroleiros com os governos trabalhistas para melhor qualificá-la. Na última parte, iremos expor as nossas hipóteses provisórias acerca do problema suscitado. A principal delas é a de que o sentido geral da ação dos petroleiros nos governos do PT é social-democrata, na medida em que se engajaram na defesa de um projeto de desenvolvimento econômico cujos resultados deveriam se espraiar pela sociedade e serem usufruídos pelos trabalhadores.

\section{SINDICALISMO E GOVERNOS DO PT}

Há uma farta bibliografia que discute a crise do sindicalismo desde os anos 1990. Assim, as transformações desse movimento aparecem associadas a diferentes fenômenos da chamada "década neoliberal": aos efeitos da inserção da economia brasileira no mercado globalizado (processo de abertura comercial) (CARDOSO, 2003); à reestruturação produtiva (DRUCK, 1995); às reformas de cunho neoliberal (BOITO, 1996; ALVES, 2002); à reconfiguração do sindicalismo por meio dos movimentos de oposição e convergência entre a CUT e a Força Sindical (COMIM, 1995; SANTANA, 1999); e ao surgimento de um novo padrão de ação sindical nomeado de neocorporativo (BOITO, 1994; GALVÃO, 1996), a cooperação-conflitiva (RODRIGUES, 1995, 2002) ou o sindicalismo cidadão (OLIVEIRA, 2011). 
No entanto, os problemas recentes do sindicalismo brasileiro têm sido encarados como se tivessem surgido com a chegada do PT ao governo federal no início dos anos 2000. Ao longo dessa década, avolumaram-se estudos acerca da relação do sindicalismo com os governos petistas. O fato é que o problema da crise dos sindicatos (MARTINS RODRIGUES, 2002) - uma das questões centrais da sociologia do sindicalismo no fim dos anos 1990 - passou a dividir espaço com indagações acerca do comportamento do movimento sindical sob os governos trabalhistas.

Desse modo, a atuação de organizações sindicais durante os governos de Luiz Inácio Lula da Silva e Dilma Rousseff foi amplamente estudada na última década. Em um primeiro plano, podem ser destacados os estudos que privilegiaram a relação da Central Única dos Trabalhadores (CUT) com o governo federal. Em segundo lugar, mas não menos importantes, aparecem as investigações sobre o desempenho do movimento sindical nos últimos anos. De um modo ou de outro, ambas as linhas procuraram entender o caráter da relação do sindicalismo com os governos petistas e quais seriam as consequências dessa associação para o poder do movimento sindical brasileiro ${ }^{2}$.

Tomando como referência o primeiro governo do PT, Ramalho, Rodrigues e Conceição (2008) chamaram a atenção para dados que mostram que, no ano inicial, o governo Lula não ofereceu resultados satisfatórios para os trabalhadores. Segundo esses autores, o ano de 2003 foi marcado por perdas. O desemprego subiu de 11,7\% para 12,4\%; a massa salarial caiu 5,7\% em relação ao ano anterior; e a renda média do trabalhador registrou uma contração de $12 \%$ no mesmo período.

Para esses autores, frente a esse cenário de perdas, a CUT não se mostrou passiva em relação ao governo. A central, liderando as outras

\footnotetext{
2 Apesar das expressões "movimento sindical brasileiro" ou "sindicalismo brasileiro" aludirem a um fenômeno nacional, ou seja, que representa o país inteiro, na verdade, esses termos, difundidos na sociologia do sindicalismo, se referem às organizações trabalhistas que têm representatividade e poder no cenário político urbano. Nesse sentido, essas expressões nomeiam o grupo heterogêneo, formado pelas centrais sindicais; pelas federações dos grandes setores da economia (indústria, comércio e serviços); e os sindicatos com tradição de luta na recente história política brasileira - entre os quais, se destacam as organizações dos ramos: metalúrgico, químico, bancário, petroleiro, etc.
} 
organizações de cúpula, articulou-se com setores empresariais objetivando ampliar a participação institucional com vistas a exercer maior pressão para a criação de mais postos de trabalho.

A intenção da CUT (...) era mostrar, por meio da ampliação e democratização do Conselho (com a presença de representantes dos trabalhadores e dos empresários), que a política monetária deveria levar em conta não apenas a meta de inflação, mas também o alcance das metas de crescimento econômico e de geração de empregos (RAMALHO et al., 2008, p. 35).

Segundo Ramalho, Rodrigues e Conceição, portanto, o comportamento dessa central, no primeiro governo Lula, oscilou entre o apoio e a crítica, expressando uma relativa autonomia da organização trabalhista frente ao Estado.

A relação da CUT com o governo Lula também foi alvo do interesse de Ladosky (2009). Segundo ele, a CUT viveu um difícil dilema nos anos 2000. A central dividiu-se entre defender o governo do PT com críticas ou afastar-se do poder e afirmar a autonomia dos interesses dos trabalhadores. De acordo com Ladosky, a CUT, majoritariamente controlada pela corrente Articulação Sindical (AS), continuou apoiando criticamente o governo. Internamente, a posição da central frente ao governo estava longe de ser definida pelo apoio irrestrito.

Para Ladosky, a divisão no interior da central iniciou-se com a aprovação da reforma da previdência dos servidores públicos em 2003. Em consequência dessa aprovação, algumas correntes de setores da esquerda começaram a promover rompimentos. O descontentamento com as políticas de caráter neoliberal do recém-empossado governo trabalhista explica a saída da central e a fundação, em 2004, da Conlutas (Coordenação Nacional de Lutas); da Intersindical em 2006; e a criação da Central dos Trabalhadores e Trabalhadoras do Brasil (CTB) em $2007^{3}$.

${ }^{3}$ Além dessas centrais, foram criadas, nessa década, a Nova Central Sindical de Trabalhadores (NCST) em 2005. A NCST teria se originado de "entidades ligadas ao sistema confederativo, 
Os impactos do surgimento de novas centrais sindicais sobre o movimento sindical foram analisados por Galvão (2009). Para essa autora, a proximidade do sindicalismo com o governo Lula e a fragmentação do movimento sindical "ao invés de fortalecer a capacidade de organização e resistência dos trabalhadores e de seus organismos de representação, tem evidenciado suas debilidades" (GALVÃO, 2009, p. 179). A manifestação dessa debilidade poderia ser observada na "acomodação da Central Única dos Trabalhadores (CUT) frente às medidas antipopulares do governo Lula" (GALVÃO, 2009, p. 179).

Já Antunes e Silva (2015) consideraram o comportamento das duas maiores centrais sindicais brasileiras, a CUT e a Força Sindical (FS), durante os governos do PT. A trajetória dessas organizações teria sido marcada pela burocratização. Nas últimas décadas, as direções da CUT e da FS teriam privilegiado a estratégia de participação institucional. Isso teria como implicação o enfraquecimento da autonomia e da independência relativa ao Estado e ao governo.

Participando de ministérios e secretarias nos âmbitos federal, estadual e municipal, elegendo-se para cargos de representação parlamentar, participando ativamente na gestão de fundos de pensão e dos conselhos de empresas estatais etc., o sindicalismo que propugnava a autonomia e a independência sindical frente ao estado, no caso da CUT, e o pretenso antiestatismo neoliberal propugnado pela Força Sindical, acomodaram-se muito bem nos aparatos burocrático-ministeriais dos governos do PT (ANTUNES; SILVA, 2015, p. 512).

\footnotetext{
historicamente contrárias a mudanças na estrutura sindical", que se uniram com "o objetivo de reagir 'às tentativas do governo Lula de acabar com a atual organização sindical pela revogação do Artigo $8^{\circ}$ da Constituição Federal' (Nova Central Sindical De Trabalhadores, 2005)" (GALVÃO, 2009, p. 189). A União Geral dos Trabalhadores (UGT) se originou em 2007 da fusão das seguintes organizações: “Confederação Geral dos Trabalhadores (CGT), Social Democracia Sindical (SDS), Central Autônoma de Trabalhadores (CAT) e de um amplo grupo de sindicatos independentes" (SOARES, 2013, p. 545). No ano seguinte, 2008, surgiu a Central dos Sindicatos Brasileiros (CSB).
} 
A relação das centrais sindicais com os governos do PT também foi estudada por Soares (2013), para quem as organizações de cúpula foram cooptadas. Desse modo, tornaram-se um importante sustentáculo político em detrimento dos interesses da classe trabalhadora. $\mathrm{O}$ imobilismo das centrais teria favorecido o avanço da reestruturação produtiva, da flexibilização e a precarização das relações de trabalho durante aquele período. ${ }^{4}$ Em síntese o ponto de vista desse autor ressalta que

o apoio das centrais sindicais ao governo as impede de apresentar reivindicações mais ousadas e por isso tem se limitado a negociar favoravelmente à ordem vigente. Assim, priorizam mais o diálogo e a negociação com o governo (política de concertação social), em vez organizar e mobilizar os trabalhadores para o enfrentamento contra o patronato e o sistema sociometabólico do capital (SOARES, 2013, pp. 560-561).

Braga (2016) concentrou-se, do mesmo modo, na relação da CUT com os governos petistas, destacando a burocratização e a falta de independência da central em relação ao governo. Braga aponta que essa organização se manteve ao lado do governo Lula mesmo depois da implementação de uma série de medidas nocivas à classe trabalhadora. $\mathrm{E}$, ainda que possa se identificar um caráter social na política neoliberal dos governos do PT - representado pelo Programa Minha Casa Minha Vida; o Programa Universidade para Todos (ProUni); a formalização do mercado de trabalho (que, segundo o autor, se deu com base na criação de

\footnotetext{
4 Inspirado em Gramsci o autor acredita que estes fatos evidenciariam o fenômeno do transformismo. "Entendemos por transformismo, no sentido gramsciano, o movimento de cooptação política e ideológica desencadeado pelas classes dominantes sobre suas forças aliadas e/ou sobre as classes subalternas. Tal movimento de aproximação com o governo consiste em atrair para o campo político dominante os intelectuais orgânicos dos outros grupos sociais, seus dirigentes políticos e ideológicos, esvaziando sua postura crítica e decapitando as forças sociais oponentes de sua direção política. Desse modo, permite-se a conservação da ordem numa qualidade superior, pois as contradições sociais e a luta entre as classes não desdobram no plano da luta política e ideológica, ficando como que 'congeladas' no plano político (...)" (SOARES, 2013, p. 548).
} 
empregos precários) - essa política teve como contrapartida a submissão à lógica do capital financeiro. Assim, a mais importante central sindical do país não apenas não enfrentou a continuidade das políticas neoliberais dos governos de Lula e Dilma, como também transformou seus dirigentes em "parceiros políticos do Estado na formulação de políticas públicas e na gestão de investimentos capitalistas por meio dos fundos de pensão" (BRAGA, 2016, p. 63).

O interesse de Boito, Galvão e Marcelino (2009) não foi apenas a relação da CUT com o governo, mas o estudo do comportamento do sindicalismo na década de 2000. Porém, também para esses autores o sindicalismo acomodou-se frente à política neoliberal dos governos petistas. Tal acomodação teve como contrapartida um projeto de reforma sindical que dotaria as direções de mais poder para controlar suas bases: "O governo Lula reformou também parte da legislação sindical, de modo a dotar à direção das centrais sindicais de um controle maior sobre as suas bases e de modo a provê-las com fundos financeiros vultuosos" (BOITO et al., p. 37).

Para Ladosky e Oliveira (2014), o comportamento do movimento sindical durante os governos do PT pode ser caracterizado pela ambiguidade. Assim, de um lado, destacam as conquistas econômicas obtidas pela atuação das centrais. Por outro lado, reconhecem que pouco ou nada se fez para alterar as graves ameaças de flexibilização das relações trabalhistas durante o período.

Considera-se que a pressão exercida pelas centrais sindicais teve influência para a correção da tabela do imposto de renda, o aumento de recursos destinados à agricultura familiar e o persistente aumento do salário-mínimo. Admitese, também, que as negociações coletivas, em importantes setores da economia, foram espaços de recuperações de perdas anteriores. Mas, por outro lado, avalia-se que, apesar de um contexto mais favorável econômica e politicamente, o sindicalismo não tem sido capaz de aproveitá-lo de modo a produzir mudanças mais estruturais nas condições e relações de trabalho no país (LADOSKY; OLIVEIRA, 2014, p. 168). 
Por fim, Cardoso (2015) também analisou a relação da CUT com os governos do PT. Para esse autor as escolhas dos dirigentes dessa organização foram condicionadas por circunstâncias históricas bem particulares, a principal delas é que a CUT e o PT formaram-se no processo de redemocratização, têm projetos semelhantes e chegaram juntas ao poder: "A CUT não foi cooptada pelo governo. Ela chegou ao poder com Lula, e tornou-se um importante manancial de novas elites, agora de extração popular, com lastro no mundo do trabalho, aptas à gestão do Estado capitalista" (CARDOSO, 2015, p. 508).

Entendemos que esse apanhado nos permite apontar pelo menos duas perspectivas sobre a relação do sindicalismo com os governos do PT. De acordo com o primeiro ponto de vista, a CUT em particular, e as organizações sindicais, em geral, obtiveram conquistas no plano econômico, como bem atestam os resultados das negociações coletivas no período, mas tiveram um comportamento em relação ao governo marcado pela acomodação e debilidade política (GALVÃO, 2009; BOITO et al., 2009), pela negação de ideais originários (transformismo) e pela cooptação (ANTUNES, SILVA, 2015; BRAGA, 2016; SOARES, 2013).

A segunda perspectiva buscou captar as contradições da relação da maior central sindical brasileira com o governo do partido dos trabalhadores (RAMALHO et al., 2008; LADOSKY, 2009; LADOSKY, OLIVEIRA, 2014). De acordo com essa visão, as escolhas dos dirigentes da CUT precisam ser compreendidas no complicado contexto dos anos 2000. Assim, esses autores não negaram o enfraquecimento da independência dessa central na relação com o governo, mas também não deixaram de reconhecer uma relativa autonomia no comportamento da CUT ao partido que chegou ao poder. Além disso, a própria ideia de cooptação foi colocada em xeque pelo argumento de que a central (CUT) e o partido (PT) nasceram e se desenvolveram no mesmo processo histórico político (CARDOSO, 2015). 


\section{OS PETROLEIROS NOS GOVERNOS DO PT}

A primeira década deste século, certamente, pode entrar para a história como um decênio marcado por importantes transformações políticas, econômicas e sociais. E o movimento sindical foi um importante ator nessas mudanças.

Em janeiro de 2003, assume o poder um presidente oriundo do sindicalismo que governará com crescente apoio do movimento sindical. De 2003 até 2010, lideranças do movimento sindical ocuparam cargos nos mais diversos postos do governo federal - o mesmo pode-se dizer acerca do governo de Dilma. Nas duas gestões petistas, a relação entre governo federal e movimento sindical tinha como atores principais o Partido dos Trabalhadores e a Central Única dos Trabalhadores. Essa associação não era acidental. Essas duas organizações nasceram, cresceram e deram vida ao movimento de redemocratização que tomou o país entre o final dos anos 1970 e toda a década de 1980 - o PT foi fundado em 1980 e a CUT em 1983. Embora sempre tenha se declarado autônoma e independente frente a partidos e governos, a CUT apoiou pública e oficialmente a candidatura de Luiz Inácio Lula da Silva para a presidência da República em 2002. Com a vitória de Lula, o PT e a CUT chegaram juntas ao governo.

Desse modo, o que a atuação da FUP nos governos do PT pode nos revelar? Os estudos sobre a CUT já não dão conta dessas questões, uma vez que a FUP compõe a CUT?

A consideração do comportamento político da FUP justifica-se por sua representatividade ${ }^{5}$ e singularidade. No interior da CUT, os petroleiros

\footnotetext{
${ }^{5}$ Hoje a FUP é composta por dirigentes oriundos de 13 sindicatos: 1. Sindipetro-Rio Grande do Norte, 2. Sindipetro Bahia, 3. Sindipetro Minas Gerais, 4. Sindipetro Duque de Caxias, 5. Sindipetro Norte Fluminense, 6. Sindepetro São Paulo, 7. Sindipetro Paraná / Santa Catarina, 8. Sindipetro Espírito Santo, 9. Sindipetro Pernambuco / Paraíba, 10. Sindipetro-Rio Grande do Sul, 11. Sindipetro Amazonas, 12. Sindipetro Ceará e 13. Sindiquímica Paraná (Sindicatos dos Trabalhadores nas Indústrias Petroquímicas do Estado do Paraná). Os seus dirigentes são eleitos em congressos trienais por delegados de cada um dos 13 sindicatos. De acordo com informações de seu site, a Federação "representa atualmente mais de 100 mil trabalhadores do setor petróleo, entre ativos, aposentados e pensionistas do Sistema Petrobrás, além de petroleiros de empresas privadas."
} 
se destacam como uma das três principais categorias dessa central, junto aos metalúrgicos e aos bancários. Cada uma dessas três categorias tem atuações sindicais específicas graças às suas inserções setoriais particulares. Se algumas lideranças dos bancários se destacaram pela administração dos fundos de pensão dos trabalhadores, e os dirigentes metalúrgicos pela atuação no desenvolvimento de políticas de incentivo à produção de automóveis, os petroleiros se destacaram pelo projeto de desenvolvimento da indústria de petróleo e gás. Eles tinham como objetivo principal restabelecer o monopólio da Petrobras sobre os processos de exploração e produção de petróleo, com vistas a tornar a empresa o motor do desenvolvimento autônomo da nação.

Os efeitos políticos e econômicos da atuação dos petroleiros nos governos do PT não foram considerados até agora. Contudo, há indícios relevantes de que os petroleiros: 1) forjaram apoio a Lula antes que este chegasse ao poder; 2) prontificaram-se como base de apoio ao governo instalado em 2003; e 3) depositaram, nesse mandato, os anseios de terem seu objetivo principal atendido. A influência dessa categoria nos rumos da administração petista deixa-se notar já em 2003. Na composição do governo de Lula, o primeiro presidente da Petrobras foi o ex-petroleiro José Eduardo Dutra.

A análise dos congressos dos petroleiros nos permite afirmar que essa categoria tem uma forte identidade coletiva cujo núcleo é a defesa do papel da Petrobras como motor do desenvolvimento autônomo da nação. Este é o projeto de desenvolvimento da categoria exposto, por exemplo, no $6^{\circ}$ Congresso da Federação Única dos Petroleiros (CONFUP), realizado no ano 2000 .

O projeto de construção da FUP nasceu da vontade política dos petroleiros em fortalecer, cada vez mais, os momentos de mobilização e espaços de articulação das lutas em defesa dos direitos dos petroleiros e da PETROBRAS como empresa pública e de extrema importância econômica e social na construção e consolidação da soberania do país (FUP, 2000, p. 30). 
Outro elemento definidor da identidade dos petroleiros organizados pela FUP era a oposição e o combate às políticas neoliberais encarnadas pelo governo de Fernando Henrique Cardoso (FHC). No $7^{\circ}$ CONFUP, em 2001, explicitam-se críticas às políticas de privatização do governo FHC para a Petrobras.

Entre os compromissos mínimos do próximo governo popular, para nós do setor do petróleo: Deve estar o da reestatizacáão do Petróleo no Brasil, com auditoria popular sobre todas as licitações e parcerias realizadas por FHC. (...) a política de entreguismo praticada pelo governo de FHC que, para evitar uma forte resistência da sociedade brasileira, vem promovendo uma estratégia de privatização "branca" da empresa, impondo cada vez mais, através da ANP, exigências de flexibilização na estratégia de exploração e produção de óleo e gás, intensificando as pressões para que, também, se ampliem a participação das empresas privadas no setor de refino (FUP, 2001, p. 55, grifo nosso).

No $9^{\circ}$ CONFUP (2003) sob o clima de esperança trazido pela eleição de Lula, os petroleiros sugerem, que o novo governo,
(...) para implementar as mudanças e reconstruir o país, precisa recuperar os setores estratégicos como o de petróleo. Por isso, urgem a elaboração de um novo planejamento estratégico para o setor; o redirecionamento da Agência Nacional de Petróleo - ANP; e o reposicionamento da PETROBRAS como empresa suporte para o desenvolvimento e a soberania do Brasil, o que implica no fortalecimento da empresa e na valorização dos seus trabalhadores (FUP, 2003, p. 13).

Pretendiam, portanto, referendar a sustentação da presidência de Lula sem descuidar dos interesses da categoria, tendo em vista os canais de poder que se abriam. Em síntese, a resolução dos petroleiros, quando da 
chegada do PT ao poder, foi a de apoiar o governo; sob a condição de defender os interesses da categoria; e com esperanças de que esse novo governo democrático e popular propiciasse as condições necessárias para a realização de seus interesses. Ou seja, os petroleiros depositaram no mandato do PT a expectativa de ter seus objetivos realizados.

Os anseios dos petroleiros parecem ter sido ouvidos pelo presidente. De acordo com o Gráfico 1, os investimentos da Petrobras saíram da casa dos 24 bilhões de reais em 2002 e ultrapassaram os 100 bilhões de reais em 2013. Para Faria (2010), a gestão de Lula caracterizou-se por redefinir o papel econômico do Estado. Descrevendo o desempenho da indústria de petróleo e gás o autor afirma que houve uma retomada de investimentos pela estatal a partir de 2003 com efeitos importantes para esse setor da economia.

Em 2010, os resultados da nova política de investimentos da Petrobras foram destacados pelo então presidente da companhia, José Sérgio Gabrielli: "Dos 47 poços perfurados recentemente pela companhia, encontramos petróleo em 41. Na área específica do pré-sal na Bacia de Santos, dos 13 poços perfurados, obtivemos 100\% de sucesso" (apud. FARIA, 2010, p. 55). A ênfase da fala de Gabrielli é que, sem investimentos, não haveria a descoberta das reservas do pré-sal, que, como se sabe, uma vez comprovadas, colocaram o país entre os 10 possuidores maiores de reservas de petróleo do planeta. 


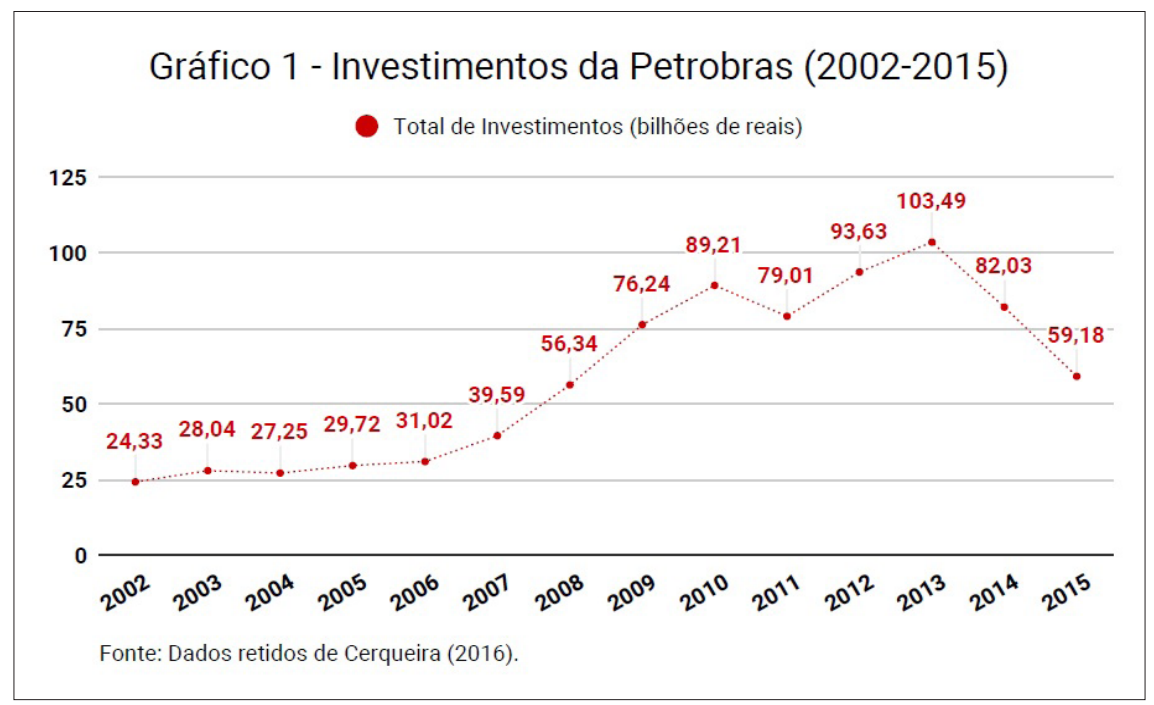

O novo papel da Petrobras na política de desenvolvimento teve efeitos positivos sobre o mercado de trabalho, em geral, e sobre a indústria naval em particular. Segundo Faria a "nova política de contratações (...) levou a estatal a ter, no final de 2007, 50 mil empregados próprios, representando um crescimento de 45,4\% desde 2003" (FARIA, 2010, p. 55). O Gráfico 2 ilustra isso.

A criação de empregos esteve, portanto, diretamente associada com a política de investimentos. Essas consequências desdobraramse, também, sobre o setor naval, por meio da encomenda de sondas de perfuração e de navios pelo "Programa de Modernização e Expansão da Frota (PROMEF), lançado em 2004” com “a liderança da Transpetro subsidiária da Petrobras. O programa já está gerando 15 mil empregos diretos e a expectativa é que este número chegue a 40 mill" (FARIA, 2010, p. 59) $)^{6}$.

\footnotetext{
${ }^{6}$ Contudo, no que diz respeito às relações de trabalho, Lopes (2012) apontou um significativo avanço da terceirização via reestruturação produtiva nas atividades da Petrobras. Segundo Lopes, o Programa de Mobilização da Indústria Nacional de Petróleo e Gás Natural (PROMINP) teve como principal alvo os trabalhadores das empresas prestadoras de serviço para a petrolífera.
} 
Citando David Fischel e Ricardo Ribeiro Pessôa, ex-presidentes da Associação Brasileira de Engenharia Industrial, Faria reforçou a importância da política de investimentos. A Petrobras

(...) nos últimos anos vem ampliando significativamente seus investimentos. Após investir, em média, cerca de 0,8\% do PIB brasileiro entre 2003 e 2006, a empresa elevou essa participação para 1,3\% em 2008. Em 2009, seus investimentos deverão somar 1,9\% do PIB (...) Ter um instrumento tão poderoso à mão é um dos fatores que diferenciam o Brasil do restante do mundo nesse momento de crise, quando os países estão empreendendo esforços históricos para manter a atividade de suas economias (FARIA, 2010, p. 57).

Portanto, Faria nos oferece uma visão geral dos impactos da política de investimentos da estatal sobre a economia e o mercado de trabalho. Entendemos que o desenvolvimento dessa política tem estreita relação com o projeto dos petroleiros organizados no interior da FUP.

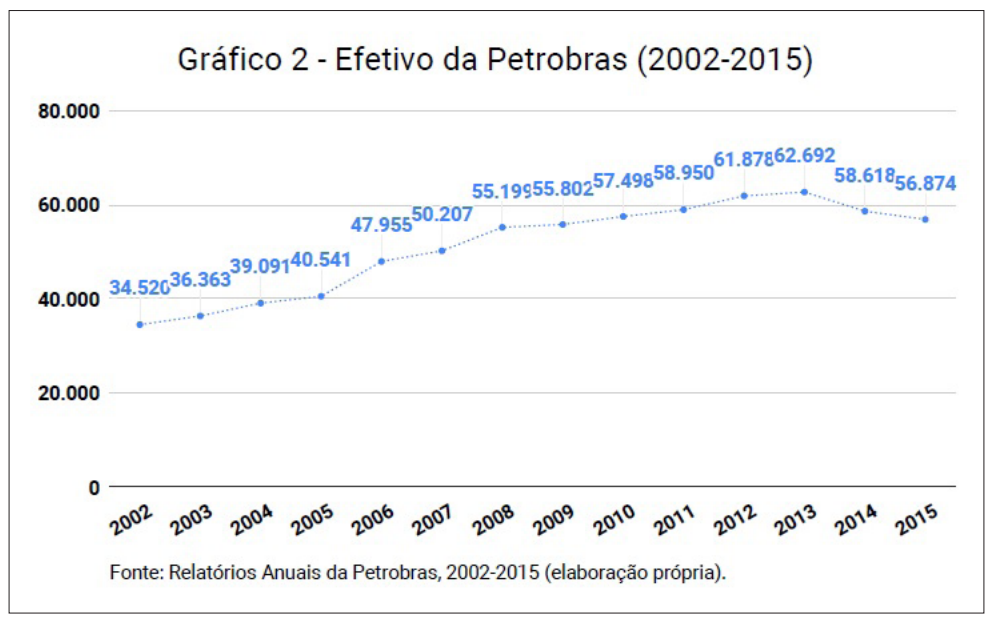

Desse modo, o PROMINP funcionou como uma justificativa para a terceirização. Isso confirma o movimento geral de flexibilização das relações de trabalho durante os governos trabalhistas, também observados por Colombi (2014); Krein e Teixeira (2016); e Malerba (2017). 
A realização do objetivo máximo dos petroleiros, todavia, parece ter encontrado resistência dentro do próprio governo. Isso ficou evidente no episódio da regulamentação do setor depois da descoberta das reservas do pré-sal. O debate sobre o marco regulatório deixou claro que havia uma disputa entre o projeto da FUP e o projeto de agentes de governo (como se vê no Quadro 1 - Propostas dos trabalhadores petroleiros e do governo para o novo marco regulatório do setor).

\begin{tabular}{|c|c|c|}
\hline Quadro 1 - Propostas dos trabalhadores petroleiros e do governo \\
para o novo marco regulatório do setor
\end{tabular}




\begin{tabular}{|c|c|c|}
\hline $\begin{array}{l}\text { Propriedade } \\
\text { do Petróleo }\end{array}$ & É do Estado brasileiro. & $\begin{array}{l}\text { Nos contratos de partilha: } \\
\text { parte é do contratante (petróleo } \\
\text { de custo e um percentual do } \\
\text { petróleo de lucro) e parte é do } \\
\text { Estado brasileiro (percentual } \\
\text { do petróleo de lucro). Nos } \\
\text { contratos de concessão: a } \\
\text { propriedade do petróleo cabe } \\
\text { ao contratante. }\end{array}$ \\
\hline $\begin{array}{l}\text { Ritmo da } \\
\text { produção }\end{array}$ & $\begin{array}{l}\text { É determinado de acordo com os } \\
\text { interesses do povo, representado } \\
\text { pelo Estado brasileiro. }\end{array}$ & $\begin{array}{l}\text { É determinado em função da } \\
\text { capacidade da indústria nacio- } \\
\text { nal internalizar os benefícios } \\
\text { do crescimento da indústria do } \\
\text { petróleo. }\end{array}$ \\
\hline
\end{tabular}

Fonte: DIEESE, 2009. (*Conselho Nacional de Política Energética. ** Agência Nacional de Petróleo.)

A comparação dos projetos evidencia uma divergência nos itens mais importantes: "Modelo de contratação das atividades de E\&P (Exploração e Produção)"; "Blocos já leiloados"; e "Propriedade do Petróleo". A disposição dos petroleiros manteve-se fiel ao seu objetivo máximo, o conteúdo de suas propostas para cada um desses temas implicava no restabelecimento do monopólio estatal sobre o setor.

A lei que redefiniu o lugar do Estado e das empresas privadas na exploração do petróleo no Brasil foi sancionada em 2010, prevalecendo o projeto do governo. Os petroleiros não conseguiram restabelecer o monopólio. No entanto, conseguiram um objetivo parcial: a "utilização do petróleo (...) em prol do desenvolvimento do país e melhoria da qualidade de vida de nossa população". Esse objetivo foi contemplado pela Lei 12.351 de $2010^{7}$.

\footnotetext{
7 “Artigo 47. É criado o Fundo Social - FS, de natureza contábil e financeira, vinculado à Presidência da República, com a finalidade de constituir fonte de recursos para o desenvolvimento social e regional, na forma de programas e projetos nas áreas de combate à pobreza e de desenvolvimento: I - da educação; II - da cultura; III - do esporte; IV - da saúde pública; V - da ciência e tecnologia; VI - do meio ambiente; e VII - de mitigação e adaptação às mudanças climáticas". Disponível em: <http://www.planalto.gov.br/ccivil_03/_Ato20072010/2010/Lei/L12351.htm>. Acesso em: 25 ago. 2018.
} 
Do ponto de vista das relações internas do sindicalismo petroleiro, os anos 2000 também são marcados por controvérsias. Em 2006, aconteceu uma dissidência no interior da FUP. Sindicatos descontentes com a repactuação do plano de previdência saíram da FUP para fundar outra organização de cúpula, a Federação Nacional dos Petroleiros ${ }^{8}$ (FNP).

A questão previdenciária ligada ao indicativo de repactuação foi o estopim da cizânia. Parte dos sindicatos repudiou a medida. O Sindicato dos Petroleiros do Litoral Paulista (Sindipetro-LP) decidiu em reunião que não participaria do Congresso, em virtude da proposta de repactuação. Os sindipetros do Rio de Janeiro, Pará/Amazonas/Maranhão/ Amapá, Alagoas/Sergipe e São José dos Campos abandonaram o congresso sem participar dos debates. Em agosto de 2006, os sindicatos dissidentes convocaram as bases para discutir a desfiliação à FUP (BATISTA, 2018, pp. 76-77).

No que se refere ao comportamento paredista dos petroleiros, ao longo dos anos 2000, houve uma diminuição das paralisações. Nessa década,

Essa norma, de 2010, foi alterada pela Lei 13.365/2016. Segundo a agência de notícias do Senado: "A proposta, de autoria do senador José Serra (PSDB-SP), tramitou no Senado em regime de urgência. (...) Pela lei anterior, de 2010, a Petrobras atuava como operadora única dos campos do pré-sal, com uma participação de pelo menos 30\%” (Disponível em: <https://www12.senado.leg.br/noticias/materias/2016/11/30/sancionada-lei-que-revogaobrigatoriedade-de-exploracao-do-pre-sal-pela-petrobras $>$. Acesso em 11 jul. 2019).

Em julho de 2018, ocorreu um leilão de oito campos de petróleo sob o marco regulatório de 2016. De acordo com Pereira (2018), esses campos abrangem uma "área de $7.977 \mathrm{~km}^{2}$ e estima-se, segundo ANP, um volume de reservas de petróleo de cerca de 12 bilhões de barris (...)." Sem a participação da Petrobras na exploração desses campos, "estima-se perdas para a União de cerca de $\mathrm{R} \$ 500$ bilhões de arrecadações nos 30 anos de produção destes campos. No que tange ao volume de royalties e recursos gerados ao Fundo Social (destinados a Saúde e Educação) as perdas são da ordem de R \$ 25 bilhões sem a participação da Petrobras" (PEREIRA, 2018, p. 98).

${ }^{8}$ Em 2010, foi fundada a Federação Nacional dos Petroleiros (FNP). Essa Federação reúne cinco sindicatos em sua base: 1. Sindipetro Alagoas e Sergipe, 2. Sindipetro Litoral Paulista, 3. Sindipetro São José dos Campos, 4. Sindipetro Pará, Amazonas, Maranhão e Amapá e 5. Sindipetro Rio de Janeiro. 
o número de greves com a base nacional unificada foi apenas de 19 dias; se compararmos com o número de dias parados da década anterior, 111 ao todo, constata-se uma diminuição significativa. Assim, a descentralização das mobilizações petroleiras, nessa década, explicar-se-ia em parte pela divisão do movimento. Ademais, essa dissidência se explicaria pelo fato de a FUP estar muito mais alinhada com os governos do PT em comparação com as gestões de FHC, durante as quais a categoria petroleira adotou uma atitude de oposição e combate às políticas de privatização do patrimônio da Petrobras (LOUREIRO; TROJBICZ, 2018).

Contudo, na década que se inicia com a eleição de Dilma Rousseff, como presidenta eleita para o terceiro mandato consecutivo do PT, os petroleiros mudaram de comportamento. No início de seu governo, Dilma experimentava uma relativa calmaria na relação com o movimento petroleiro. Houve uma ameaça de greve em 2011, mas, com a conclusão das negociações do Acordo Coletivo de Trabalho (ACT), não ocorreu paralisação.

As negociações do ACT em 2013, no entanto, foram muito diferentes. Dessa vez, houve mobilização e enfrentamento político contra as atitudes do governo; o resultado foi a paralisação das atividades dos petroleiros durante sete dias consecutivos em todo o país, a maior paralisação desde a histórica greve de 1995. O motivo da paralisação foi a retomada de leilões de campos de petróleo, que não ocorriam desde 2008, quando o pré-sal foi descoberto. Após sete dias de greve, com muita resistência e mobilização, houve enfrentamento dos petroleiros com as forças armadas em frente à sede da Petrobras, na cidade do Rio de Janeiro, no dia da realização do leilão do Campo de Libra, um dos lotes com maior potencial produtivo das recém-descobertas reservas do pré-sal.

Os protestos não cessaram depois de 2013. No ano de 2015, o número de dias de greve ultrapassou os sete dias de 2013, e os petroleiros conseguiram fazer com que a Petrobras aceitasse a criação de um Grupo de Trabalho para discutir o que chamaram de Pauta Pelo Brasil com o objetivo de 
(...) negociar junto à Petrobras caminhos e alternativas para evitar a venda de ativos, manter os empregos e investimentos. A Petrobras ignorou os petroleiros por mais de cem dias após a entrega do documento citado acima. A Federação Única dos Petroleiros fez uma greve de advertência no dia 24 de julho de 2015 em função do impasse nas negociações do Acordo Coletivo de Trabalho. Nas rodadas de negociação de todas as cláusulas do Acordo Coletivo 2015-2017, a Petrobras sinalizou cortar direitos. Os sindicalistas petroleiros ao mesmo tempo quiseram tanto negociar o Acordo Coletivo de Trabalho quanto a pauta política para a Petrobras através da Pauta Pelo Brasil. Isto reforçou e sinalizou a preocupação do movimento sindical petroleiro (...) com os interesses sociais mais amplos (...). A greve de 2015 teve início em $1^{\circ}$ de novembro de 2015 e em alguns sindicatos foi feita até o dia 20 de novembro de 2015 (PARANHOS, 2016, p. 116).

Portanto, o potencial paredista dos petroleiros, manifestouse primeiro contra a reabertura de leilões de campos de exploração de petróleo em 2013, depois contra a queda nos investimentos da estatal, em 2015, numa greve que, isoladamente, por 20 dias, superou o período total das greves da categoria unificada na década anterior (de 19 dias). A queda de investimentos é particularmente sensível para a categoria, tendo em vista o impacto desses no mercado de trabalho. De acordo com o Gráfico 2, entre 2013 e 2015, foram eliminados 5.818 postos de trabalho na Petrobras. Entretanto, devemos considerar que o impacto no mercado de trabalho deve ser bem maior se considerarmos a cadeia de produção de petróleo da qual a Petrobras é fundamental (FARIA, 2010).

Tendo em vista esses fatos, bem como o apanhado bibliográfico a respeito do recente desempenho do sindicalismo brasileiro, podemos caracterizar a ação sindical nesse período como prenhe de contradições. A breve consideração por nós efetuada da relação dos petroleiros com os governos do PT também evidenciou paradoxos. 


\section{À GUISA DE CONCLUSÃO}

A nosso ver, a chegada do PT ao poder ensejou a concretização do projeto da FUP. O fato de um partido formado pela luta dos interesses dos trabalhadores ter alcançado ao poder representava uma possibilidade concreta de realização do projeto dos petroleiros. Nesse sentido, a ascensão do PT significou o alargamento das possibilidades de se efetuar os interesses dos trabalhadores, e não o contrário. Assim, nada mais natural do que o fato de esse governo ter contado com o engajamento de uma importante categoria, que também se formou na luta pela democracia e contra a intrusão das instituições do corporativismo (BRANT et al., 1990). Isso não significa, necessariamente, cooptação ou transformismo. O fato de os petroleiros terem se mobilizado contra a reabertura dos leilões (2013), os cortes de investimento (2015) e organizarem um projeto concorrente ao do governo, na ocasião de regulamentação da exploração do pré-sal em 2010, relativiza a tese de enfraquecimento da autonomia organizativa.

Uma geração de sindicalistas chegou ao poder junto com o PT (CARDOSO, 2015), e o primeiro presidente da Petrobras foi um expetroleiro, de modo que essa categoria se tornou relevante para o governo. Ser governo e defendê-lo, sem abrir mão de seus interesses, por sua vez, tornou-se um elemento valoroso da identidade desse grupo, a qual se construiu, também, negando o chamado projeto neoliberal de Fernando Henrique Cardoso. Porém, participar do governo pode ter limitado a FUP a se opor a esse apenas nas instâncias internas. Por outro lado, isso não significou total submissão dos petroleiros ao poder constituído, pois, se eles fossem totalmente subservientes, não teriam feito um plano contrário àquele elaborado pelo governo petista, quando se buscava a redefinição do marco regulatório ensejado pela descoberta do pré-sal. Essa descoberta, aliás, foi possibilitada pela política de ampliação de investimentos da Petrobras defendida pela própria FUP (FARIA, 2010). Ademais, não foi de somenos importância a política de investimentos proposta pelos petroleiros, a qual teve um impacto positivo na criação de postos de trabalho e no crescimento da indústria naval e setores adjacentes. Esses foram os êxitos do projeto dos petroleiros, e a defesa desses atrelou esse grupo ainda mais ao governo.

Temáticas, Campinas, 27, (53): 225-250, fev./jun. 2019 
Esses resultados e, sobretudo, a criação de postos de trabalho na indústria de petróleo e gás e ramos adjacentes da economia, permitem-nos aventar a hipótese de que o caráter geral da ação sindical dos petroleiros, através de sua trajetória no governo do Partido dos Trabalhadores, pode ser definida como social-democrata (PRZEWORSKI, 1989), na medida em que um de seus objetivos - "pleno emprego, melhor distribuição de renda, inclusão social e grandes investimentos em educação, saúde e na melhoria das condições de vida da população" - foi relativamente atingido. Segundo Przeworski (1989), quando a social-democracia se torna governo, um de seus compromissos principais é com a produção e distribuição de riqueza por meio do estímulo aos investimentos e ao desenvolvimento econômico. Parece-nos que não era outro o significado geral da ação dos petroleiros, daí a importância central da Petrobras em seu projeto. Pois uma empresa totalmente sob o controle do Estado, governado por trabalhadores e, portanto, com autonomia para investir, constitui-se uma peça fundamental para a promoção do desenvolvimento econômico com autonomia.

\section{REFERÊNCIAS BIBLIOGRÁFICAS}

ALVES, G. Trabalho e sindicalismo no Brasil: um balanço crítico da 'década neoliberal' (1990-2000). Rev. Sociol. Polit., Curitiba, v.19, pp. 71-94, 2002.

ANTUNES, R. e SILVA, J. B. Para onde foram os sindicatos? Do sindicalismo de confronto ao sindicalismo negocial. $C R H$, Salvador, v. 28 , n. 75 , pp. $511-528,2015$.

BATISTA, C. A estratégia da negação: o lulismo e a dissidência sindical petroleira. Tese (Doutorado em Ciências Jurídicas e Sociais), Programa de Pós-Graduação em Sociologia e Direito, Universidade Federal Fluminense, Niterói, 2018.

BOITO, A. et al. Brasil: o movimento sindical e popular na década de 2000. OS AL, Buenos Aires: CLACSO v. 10, n. 26, 2009. 
BOITO, A. A. De volta para o novo corporativismo, a trajetória política do sindicalismo brasileiro. São Paulo em Perspectiva, São Paulo: Fundação SEADE, v. 9, n. 3, pp. 116-126, 1994.

BOITO, A. A. Hegemonia neoliberal e sindicalismo no Brasil. Crítica Marxista, São Paulo: Brasiliense, v.1, n.3, pp .80-105, 1996.

BRAGA, Ruy. Terra em transe: o fim do lulismo e o retorno da luta de classes. In: As contradições do lulismo: a que ponto chegamos? Org.: André Singer e Isabel Loureiro. $1^{a}$ edição, São Paulo: Boitempo, 2016.

BRANT, V. C. et al. Paulinia, petróleo e política. Campinas/São Paulo, Sindicato dos Petroleiros de Paulínia e Campinas / Cebrap, 1990.

CARDOSO, A. A Década Neoliberal e a crise dos sindicatos no Brasil. São Paulo, Boitempo, 2003.

CARDOSO, A. Dimensões da crise do sindicalismo brasileiro. CRH, Salvador, v. 28, n. 75, pp. 493-510, 2015.

CERQUEIRA, B. Política fiscal, demanda agregada, crescimento e crise: o investimento federal e o investimento da Petrobras no período 2003-2015. Instituto de Economia da UFRJ, texto para discussão n. 27, 2016. Disponível em: < http://www.ie.ufrj.br/images/pesquisa/ publicacoes/discussao/2016/TD_IE_027_2016_CERQUEIRA. pdf >. Acesso em: 11 jul. 2019.

COLOMBI, A. P. Entre a fragmentação e ação unificada: uma análise da atuação do Sindicato dos Bancários e Financiários de São Paulo, Osasco e região durante os anos 2000. Dissertação (Mestrado em Desenvolvimento Econômico) - Universidade Estadual de Campinas, Instituto de Economia, 2014.

COMIN, A. A estrutura sindical corporativa: um obstáculo à consolidação das centrais sindicais no Brasil. Dissertação (Mestrado em Sociologia) Faculdade de Filosofia, Letras e Ciências Humanas, Universidade de São Paulo, 1995. 
COSTA, Hermes Augusto. O sindicalismo contemporâneo entre as tipologias e as formas de acção. Estudos de sociologia, Araraquara, v.16, n.31, pp. 341-362, 2011.

DIEESE - Departamento Intersindical de Estatística e Estudos Socioeconômicos. Desafios rumo à construção de uma nova legislação para a indústria de petróleo e gás natural no Brasil. Estudos e Pesquisas, n. 48. São Paulo: DIEESE, 2009. Disponível em: < https://www.dieese.org. br/estudosepesquisas/2009/estPesq48petroleoGas.pdf >. Acesso em: 9 jul. 2018.

DRUCK, G. Terceirização: (des)fordizando a fábrica - um estudo do complexo petroquimico da Babia. Tese (Doutorado em Ciências Sociais) Departamento de Ciências Sociais e Humanas da Universidade Estadual de Campinas, Campinas, 1995. Disponível em: < http:// www.bibliotecadigital.unicamp.br/document/list. $\quad$ php?tid $=28>$. Acesso em: 22 abr. 2015.

FARIA, G. O governo Lula e o novo papel do Estado brasileiro. São Paulo: Editora Fundação Perseu Abramo, 2010.

FIORI, J. L. C. Petróleo: uma decisão urgente. In: LEÃO, Rodrigo; NOZAKI, William (orgs.). Geopolítica, estratégia e petróleo: transformacões internacionais e nacionais. Rio de Janeiro: INEEP; FLACSO, pp. 31-33, 2019.

FUP. $6^{\circ}$ CONFUP. 16, 17 e 18 de junho de 2000 Belo Horizonte - MG. Disponível em: < https://www.fup.org.br/forum/confup/vi-confup $>$. Acesso em: 28 ago. 2018.

FUP. $7^{\circ}$ CONFUP, PRIVATIZAR FAZ MAL AO BRASIL. 29, 30 de junho e 01 Julho de 2001 Porto Alegre - RS. Disponível em: < https://www.fup.org.br/forum/confup/vii-confup >. Acesso em: 28 ago. 2018.

FUP. $9^{\circ}$ CONFUP, PETROLEIROS: 50 ANOS CONSTRUINDO A HISTÓRIA DA PETROBRÁs 10, 11, 12 e 13 de julho de 2003. 
Campinas-SP. Disponível em: < https://www.fup.org.br/forum/ confup/ix-confup >. Acesso em: 28 ago. 2018.

GALVÃO, A. Participação e fragmentação: a prática sindical dos metalúrgicos do $A B C$ nos anos 1990. Dissertação (Mestrado em Ciências Sociais) Universidade Estadual de Campinas, 1996. Disponível em: < http:/ / www.bibliotecadigital.unicamp.br/document/list. $\quad$ php?tid $=28 \quad>$. Acesso em: 22 abr. 2015.

GALVÃO, A. A reconfiguração do movimento sindical no governo Lula. Outubro, Campinas, n. 18, p.177-200, 2009. Disponível em: < http:// outubrorevista.com.br/a-reconfiguracao-do-movimento-sindical-no-governolula/>. Acesso em: 12 mai. 2015.

KREIN, J. D, TEIXEIRA, M. As controvérsias das negociações coletivas nos anos 2000 no Brasil. In: OLIVEIRA, R. V., BRIDI, M. A., FERRAZ, M. (Orgs.). O sindicalismo na era Lula: paradoxos, perspectivas e olhares. Belo Horizonte: Editora Fino Traço, 2016, pp. 213-246.

LADOSKY, M. H. A CUT e o Governo Lula: Da defesa da "liberdade e autonomia" à reforma sindical inconclusa. Tese (Doutorado em Sociologia), Faculdade de Filosofia Letras e Ciências Humanas, Universidade de São Paulo, 2009. Disponível em: < http://www.teses.usp.br/index. php?lang=pt-br $>$. Acesso em: 9 de dez. 2016.

. OLIVEIRA, R, V. O "novo sindicalismo" pela ótica dos estudos do trabalho. Revista Mundos do Trabalho, vol. 6, n. 11, pp. 147-170, 2014.

LOUREIRO, I. e TROJBICZ, B. Rupturas, continuidades e gradualismo nas políticas de petróleo no Brasil: 1995 a 2010. O\& S. Salvador, v. 25, n. 85, pp. 193-210, 2018.

MALERBA, P. E. O sindicalismo bancário nos governos do PT. Tese (Doutorado em Ciência Política) - Universidade Estadual de Campinas, Instituto de Filosofia e Ciências Humanas, 2017.

MARTINS RODRIGUES, Leôncio. Destino do Sindicalismo. São Paulo: Edusp/Fapesp, 2002. 
OLIVEIRA, R. V. Sindicalismo e democracia no Brasil: do novo sindicalismo ao sindicato cidadão. São Paulo: Annablume Editora, 2011.

PARANHOS, M. Mobilização e ação sindical: a Federação Única dos Petroleiros (FUP) e a negociação coletiva para o acordo 2013-2015. Tese (Doutorado em Sociologia), Programa de Pós-Graduação em Sociologia e Antropologia do Instituto de Filosofia e Ciências Sociais da Universidade Federal do Rio de Janeiro, 2016.

PEREIRA, C. Leilão do pré-sal: a vez das petroleiras americanas. In: LEÃO, R., NOZAKI, W. (orgs.). Energia e petroliferas globais: transformações e crise. Rio de Janeiro: INEEP - FLACSO, pp. 93-98, 2018.

PRZEWORSKI, A. Capitalismo e Social-Democracia. São Paulo: Companhia das Letras, 1989.

RAMALHO, J. R. et al. Relações de trabalho e sindicato no primeiro governo Lula (2003-2006). Ciência e Cultura, v. 60, pp. 54-57, 2008.

RODRIGUES, I. J. Um laboratório de relações de trabalho: o ABC paulista nos anos 90. Tempo Social, São Paulo, v. 14, n.1, pp. 137-157, 2002.

RODRIGUES, I. J. O sindicalismo brasileiro: da confrontação à cooperação conflitiva. São Paulo em Perspectiva, São Paulo: Fundação SEADE, v. 9, n. 3, pp. 116-126, 1995.

ROMÃO, F. A Greve do fim do mundo: petroleiros 1995 - Expressão fenomênica da crise fordista no Brasil. Tese (Doutorado em Sociologia), Instituto de Filosofia e Ciências Humanas, - Universidade Estadual de Campinas, 2006.

SANTANA, M. A. Entre a ruptura e a continuidade: visões da história do movimento sindical brasileiro. RBCS, v. 14, n. 41, pp. 103-120, 1999.

SOARES, J. As centrais sindicais e o fenômeno do transformismo no governo Lula. Revista Sociedade e Estado, Brasília, vol. 28, n. 3, pp. 541564, 2013.

Texto recebido em 16/02/2019 e aprovado em 30/06/2019 